\title{
Lack of Effect of 12-Week Treatment with Risankizumab on the Pharmacokinetics of Cytochrome P450 Probe Substrates in Patients with Moderate to Severe Chronic Plaque Psoriasis
}

\author{
Amit Khatri ${ }^{1} \cdot$ Ling Cheng ${ }^{2} \cdot$ Anne Camez $^{3} \cdot$ Stanislav Ignatenko ${ }^{4} \cdot$ Yinuo Pang ${ }^{1} \cdot$ Ahmed A. Othman $^{1}$
}

Published online: 21 December 2018

(c) The Author(s) 2018

\begin{abstract}
Objective The objective of this study was to characterize the effects of risankizumab on the in vivo activity of cytochrome P450 (CYP) 1A2, CYP2C9, CYP2C19, CYP2D6, and CYP3A in psoriasis patients using a cocktail approach.

Methods Patients with moderate to severe chronic plaque psoriasis $(n=21)$ received single oral doses of sensitive probe substrates for CYP1A2 (caffeine $100 \mathrm{mg}$ ), CYP2C9 (warfarin $10 \mathrm{mg}$ ), CYP2C19 (omeprazole 20 mg), CYP2D6 (metoprolol $50 \mathrm{mg}$ ), and CYP3A (midazolam $2 \mathrm{mg}$ ) on day 1, followed by 12 weeks of subcutaneous risankizumab treatment of $150 \mathrm{mg}$ once every 4 weeks from day 8 to day 92, and again the same cocktail of substrates on day 98. Serial blood samples were collected for determination of the CYP probe drugs and metabolites with and without risankizumab. Trough samples were collected for risankizumab. Results The $90 \%$ confidence intervals (CIs) for the area under the plasma concentration-time curve (AUC) from time zero to infinity $\left(\mathrm{AUC}_{\infty}\right)$ ratios for the CYP probe substrates administered with risankizumab versus without risankizumab were within the default $0.8-1.25$ equivalence bounds. Similar results were observed for maximum plasma concentration $\left(C_{\max }\right)$, except for omeprazole, for which the lower bound of the $90 \% \mathrm{CI}$ for $C_{\max }(0.73)$ extended slightly below the default equivalence limit. No differences were observed in metabolite-to-parent drug $C_{\max }$ or AUC ratios with risankizumab versus without risankizumab. Risankizumab trough plasma concentrations significantly exceeded those of the phase III regimen of risankizumab in psoriasis ( $150 \mathrm{mg}$ subcutaneously at weeks 0 and 4 and every 12 weeks thereafter).

Conclusions Risankizumab did not affect the in vivo activity of CYP1A2, CYP2C9, CYP2C19, CYP2D6, or CYP3A enzymes in patients with moderate or severe plaque psoriasis and therefore has no potential for drug interactions through these enzymes.
\end{abstract}

Clinical trial registration ClinicalTrials.gov Identifier: NCT02772601.

\section{Key Points}

12 weeks of treatment with risankizumab $150 \mathrm{mg}$ administered subcutaneously every 4 weeks had no relevant effects on cytochrome P450 (CYP) 1A2, CYP2C9, CYP2C19, CYP2D6, or CYP3A in vivo.

Ahmed A. Othman

ahmed.othman@abbvie.com

1 Clinical Pharmacology and Pharmacometrics, AbbVie Inc., 1 North Waukegan Road, North Chicago, IL 60064, USA

2 Data and Statistical Sciences, AbbVie Inc., North Chicago, IL, USA

3 Immunology Development, AbbVie Deutschland GmbH \& Co. KG, Ludwigshafen am Rhein, Germany

4 Charité Research Organisation GmbH, Berlin, Germany

No dose adjustment is needed for concomitant medications that are substrates of these CYP enzymes during coadministration with risankizumab. 


\section{Introduction}

Risankizumab is a fully humanized IgG1 monoclonal antibody that is specific for the p19 subunit of interleukin (IL)-23 [1]. IL-23 has been shown have a pivotal role in autoimmunity and inflammation through its induction of $\mathrm{T}$ helper (Th) 17 cells, which in turn have been implicated in the pathogenesis of psoriasis, Crohn's disease, ulcerative colitis, and other inflammatory diseases $[2,3]$. In a proofof-concept study, a single dose of risankizumab produced rapid and durable improvements in skin lesions in patients with moderate to severe plaque psoriasis [4]. In phase II studies, risankizumab was associated with a greater clinical response than ustekinumab in patients with moderate to severe chronic plaque psoriasis [5] and a greater clinical response than placebo in patients with psoriatic arthritis [6] or Crohn's disease [7]. Furthermore, the initial efficacy observed in psoriasis has recently been confirmed based on the results from four phase III trials showing that risankizumab achieved significantly greater rates of skin responses (84-88\% of patients with clear or almost clear skin) than ustekinumab (62-63\% of patients), adalimumab (60\% of patients), or placebo (7\%) after 16 weeks of treatment $[8,9]$. Phase III studies in Crohn's disease $[10,11]$ and ulcerative colitis [12] are currently ongoing. Risankizumab exhibits linear pharmacokinetics and has an estimated elimination half-life $\left(t_{1 / 2}\right)$ of approximately 4 weeks in patients with psoriasis [13].

Patients with immune-mediated inflammatory diseases may have co-morbidities that require treatment with multiple medications [14-16], many of which may undergo metabolism through cytochrome P450 (CYP) enzymes. Therapeutic proteins that modulate cytokine levels or signaling pathways have been hypothesized to potentially result in drug interactions with drugs that are substrates of CYP enzymes because the cytokines themselves, which are elevated in inflammatory diseases, can down-regulate the transcription of CYP genes and reduce metabolism of such drugs [17-20]. Agents that reduce or neutralize cytokines or inhibit their signaling pathways can reverse cytokine-mediated suppression of CYPs, resulting in increased clearance and decreased exposures of CYP substrates compared with those observed prior to treatment $[21,22]$. For example, the anti-IL-6 antibody tocilizumab has been shown to normalize IL-6-induced suppression of CYP enzymes in vitro [23] and to reduce the exposures of omeprazole and simvastatin in patients with rheumatoid arthritis following initiation of treatment $[21,24,25]$. Similarly, sirukumab, a monoclonal antibody that targets IL-6, has been shown to reverse IL-6-mediated suppression of CYP3A, CYP2C19, and CYP2C9 activities in patients with rheumatoid arthritis [26]. However, the evidence of potentially clinically relevant therapeutic proteins-drug interactions beyond antibodies that inhibit IL-6 signaling remains scarce.

CYP-mediated drug interactions can be evaluated using a cocktail approach in which multiple CYP probe substrate drugs are administered together in the same study. This approach allows evaluation of the effect of a drug on the in vivo activity of multiple CYP enzymes simultaneously in a relatively small number of subjects. Several CYP cocktails have been developed and validated for evaluating CYP-mediated drug interactions in vivo, each of which uses a slightly different set of probe substrates to assess the effect of the perpetrator as an inhibitor or inducer for various CYP enzymes [27]. The five-drug cocktail described by Turpault et al. [28] contains caffeine (CYP1A2 substrate), warfarin (S-enantiomer is a CYP2C9 substrate), omeprazole (CYP2C19 substrate), metoprolol (CYP2D6 substrate), and oral midazolam (CYP3A substrate) as the probe substrate drugs for in vivo CYP activity. These drugs have been shown to be safe and do not interact with each other when used in combination [28]. The aim of the study described herein was to characterize the effects of 12-week treatment with risankizumab on CYP1A2, CYP2C9, CYP2C19, CYP2D6, and CYP3A activity using the CYP cocktail approach in patients with moderate to severe chronic plaque psoriasis. The evaluated risankizumab regimen and the duration of the study were selected to cover the worst-case potential interaction scenario in subjects with psoriasis.

\section{Methods}

\subsection{Study Design and Participants}

This was an open-label, single-center study designed to evaluate the effects of coadministration of multiple doses of risankizumab on the pharmacokinetics of CYP probe substrates using a cocktail approach [28] in patients with moderate to severe chronic plaque psoriasis (ClinicalTrials.gov identifier: NCT02772601 [35]; Table 1). Patients received a single oral dose of caffeine (100 mg; two $50 \mathrm{mg}$ tablets), warfarin $(10 \mathrm{mg}$; two $5 \mathrm{mg}$ tablets), omeprazole ( $20 \mathrm{mg}$; one tablet), metoprolol (50 mg; one tablet), and midazolam ( $2 \mathrm{mg} ; 1 \mathrm{~mL}$ of oral solution) on day 1 . Beginning on day 8 , patients began receiving risankizumab $150 \mathrm{mg}$ administered subcutaneously (SC) every 4 weeks for 12 weeks (days 8-92). On day 98, approximately 1 week after the last dose of risankizumab, patients received another single oral dose of the CYP probe substrate drugs. All CYP probe substrate drugs were administered in the morning after a minimum $10 \mathrm{~h}$ fast and $4 \mathrm{~h}$ before lunch. Risankizumab was administered in the morning at the same time on each dosing day. 
Table 1 Study design $(n=21)$

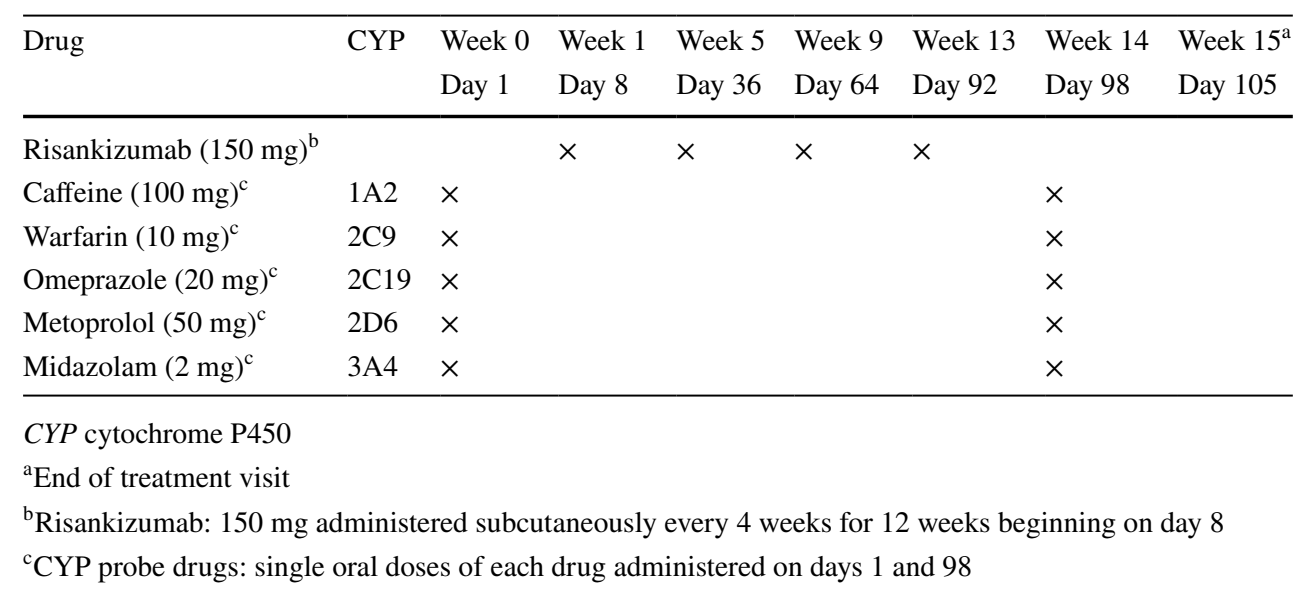

Men and women with moderate to severe chronic plaque psoriasis, defined as $\geq 10 \%$ body surface area involvement, a Psoriasis Area and Severity Index (PASI) score $\geq 12$, a static Physician Global Assessment score $\geq 3$, and a duration of at least 6 months, with or without active psoriatic arthritis, were eligible to enroll. Patients must have been 18-75 years of age at screening with a body mass index of $18.5-40.0 \mathrm{~kg} / \mathrm{m}^{2}$ and a body weight of 50-148 kg. Patients who had other forms of psoriasis, chronic or acute infections including HIV, viral hepatitis, and/or tuberculosis, a history of malignancy within the past 5 years, clinically significant laboratory abnormalities, or who had used tobacco or nicotine-containing products within 30 days of the first dose of CYP probe drugs were not allowed to enroll. Patients must not have used any known inhibitors or inducers of CYP1A2, CYP2C9, CYP2C19, CYP2D6, or CYP3A4 enzymes within 30 days or five halflives of the respective medication, or consumed any foods or dietary/herbal supplements or inhibitors of P-glycoprotein, breast cancer resistance protein, or organic anion-transporting polypeptide 1B1/1B3 transporters within 14 days or five halflives of the respective medication, whichever was greater prior to the CYP cocktail probe drug administration on days 1 and 98 and throughout the collection of plasma samples for their pharmacokinetic assessment.

Patients were confined to the study site on days -1 through 4 and days 97 through 101 for administration of the CYP probe drugs, safety assessments, and collection of pharmacokinetic blood samples. Standardized meals were provided during confinement. On all other study days, the study was performed on an outpatient basis during which the patients visited the study site every 4 weeks for administration of risankizumab.

\subsection{Pharmacokinetic Sampling and Bioanalytical Methods}

Serial blood samples for determination of CYP probe substrate and metabolite plasma concentrations were collected by venipuncture into sodium heparin-containing tubes just before dosing $(0 \mathrm{~h})$ and for up to $24 \mathrm{~h}$ after dosing for omeprazole, 5-hydroxy-omeprazole (metabolite formed by CYP2C19), midazolam, and 1-hydroxy-midazolam (metabolite formed by CYP3A); up to $48 \mathrm{~h}$ after dosing for caffeine, paraxanthine (metabolite formed by CYP1A2), metoprolol, and $\alpha$-hydroxymetoprolol (metabolite formed by CYP2D6); and up to $168 \mathrm{~h}$ after dosing for S-warfarin. Plasma concentrations of the CYP probe substrate drugs and their metabolites were determined using standard validated liquid chromatography methods with tandem mass spectroscopy (MS/MS) detection at PPD Laboratories (Middleton, WI, USA) for caffeine, metoprolol, and warfarin and AbbVie (North Chicago, IL, USA) for midazolam and omeprazole. The lower limit of quantitation (LLOQ) in plasma was $25.0 \mathrm{ng} / \mathrm{mL}$ for caffeine and paraxanthine, $5.0 \mathrm{ng} / \mathrm{mL}$ for S-warfarin, $1.07 \mathrm{ng} / \mathrm{mL}$ for omeprazole, $1.04 \mathrm{ng} / \mathrm{mL}$ for 5-hydroxy-omeprazole, $0.20 \mathrm{ng} / \mathrm{mL}$ for metoprolol and $\alpha$-hydroxymetoprolol, and $0.0504 \mathrm{ng} / \mathrm{mL}$ for midazolam and 1-hydroxy-midazolam. Samples quantified below the LLOQ were reported as zero. The bias values across the assays were $\leq 12 \%$ and the percentage coefficients of variation $(\% \mathrm{CV}$; as a measure for precision) across the assays were $\leq 14 \%$.

Blood samples for determination of risankizumab plasma concentrations and detection of risankizumab anti-drug antibody (ADA) were collected just prior to risankizumab dosing on days 8, 36, 64, 92, 105, and 204; an additional blood sample for risankizumab plasma concentrations was collected on day 98. Risankizumab plasma concentrations and ADA were measured as previously described [5, 13]. Briefly, risankizumab plasma concentrations were determined using a validated, enzyme-linked immunosorbent assay method in which a polyclonal anti-risankizumab antibody was used as the capture reagent and a biotinylated anti-idiotypic risankizumab antibody was used as the detection reagent. The assay has risankizumab quantitation range of 5-100 ng/ $\mathrm{mL}$, with a lower limit of quantification of $5 \mathrm{ng} / \mathrm{mL}$. Plasma samples above the upper limit of quantitation were diluted 
and re-assayed. The precision $(\% \mathrm{CV})$ was $<5.4 \%$ and the bias was $-0.9 \%$ to $-2.8 \%$.

For the detection of ADA against risankizumab in human plasma, a three-tiered bridging electrochemiluminescence immunoassay coupled with an acid dissociation step was used. Samples were first analyzed in a screening assay (tier 1), screen-positive samples were then analyzed in a confirmatory assay (tier 2), and, finally, confirmed positive samples were analyzed to determine the ADA titer following serial dilutions (tier 3). The ADA assay had a sensitivity of $0.219 \mathrm{ng} / \mathrm{mL}$ and drug tolerance allowed detection of $0.7 \mathrm{ng} / \mathrm{mL}$ of a positive control in the presence of $5 \mu \mathrm{g} / \mathrm{mL}$ of risankizumab.

\subsection{Pharmacogenetic Analysis of Polymorphic Cytochrome P450 Enzymes}

One $4 \mathrm{~mL}$ whole-blood sample was collected from each patient for pharmacogenetic analyses of polymorphisms in the genes encoding CYP2C9, CYP2C19, and CYP2D6. DNA was extracted using Qiagen reagent kits (Qiagen Inc., Valencia, CA, USA) applied to an AutoGenprep 3000 (AutoGen, Holliston, MA, USA) automated DNA extraction instrument. DNA samples were processed following the procedures described in the DMET ${ }^{\mathrm{TM}}$ Plus Premier Pack Protocol (Affymetrix, Santa Clara, CA,USA), part number 901268, and genotypes were determined using the DMET ${ }^{\mathrm{TM}}$ Console (Affymetrix) version 1.3.0.20. CYP2D6 x2 and s5 alleles were determined using polymerase chain reaction (PCR) and gel electrophoresis [29, 30]. Polymorphisms for $C Y P 2 C 9, C Y P 2 C 19$, and $C Y P 2 D 6$ were genotyped, and the genotype data were used to predict each patient's metabolizer phenotype (poor, intermediate, extensive, or ultra-metabolizer).

\subsection{Pharmacokinetic and Statistical Analyses}

Pharmacokinetic parameters for the CYP probe substrates and metabolites were estimated using non-compartmental methods in SAS ${ }^{\circledR}$ version 9.3 (SAS Institute, Inc., Cary, NC, USA). Pharmacokinetic parameters included the maximum plasma concentration $\left(C_{\max }\right)$, time to $C_{\max }\left(t_{\max }\right)$, area under the plasma concentration-time curve (AUC) up to the last measureable concentration $\left(\mathrm{AUC}_{t}\right)$ and from time zero to infinity $\left(\mathrm{AUC}_{\infty}\right)$, as well as the terminal phase $t_{1 / 2}$. Additionally, the metabolite:parent AUC ratio was also calculated for caffeine, omeprazole, metoprolol, and midazolam.

Statistical analyses were conducted using SAS ${ }^{\circledR}$ version 9.3. To assess the effect of risankizumab on the CYP probe drugs, a repeated measures analysis was performed for the natural logarithms of $C_{\max }$, AUC t, and $\mathrm{AUC}_{\infty}$ for the CYP probe substrates and their metabolites and the metabolite:parent AUC ratios for caffeine, omeprazole, metoprolol, and midazolam (paraxanthine:caffeine, 5-hydroxy-omeprazole:omeprazole, $\alpha$-hydroxymetoprolol:metoprolol, and 1-hydroxymidazolam:midazolam, respectively). In this analysis, the pharmacokinetic parameters $\left(C_{\max }, \mathrm{AUC}_{t}\right.$, and $\left.\mathrm{AUC}_{\infty}\right)$ were treated as repeated measures, the regimen (i.e., day $1 \mathrm{CYP}$ probe drug alone and day 98 CYP probe drug coadministered with risankizuamb) was treated as a fixed effect, and subject was treated as a random effect with a compound symmetry variance structure. The central value ratios of exposures $\left(C_{\max }\right.$ and $\left.\mathrm{AUC}_{\infty}\right)$ of the CYP probe drugs or metabolite:parent AUC ratios with versus without risankizumab were determined by the point estimates and $90 \%$ confidence intervals (CIs) for the difference of the least squares means obtained from the repeated measures analyses. In addition, a sensitivity analysis was conducted for the CYP2C9, CYP2C19, and CYP2D6 probe substrates using data from extensive and ultra-metabolizers only (excluding intermediate and poor metabolizers).

\subsection{Safety Assessments}

Safety was evaluated during confinement and at each study visit through adverse event monitoring, vital signs measurements, physical examinations, and routine laboratory tests.

\section{Results}

\subsection{Participants and Demographics}

Twenty-one patients (two women and 19 men) were enrolled and completed the study. The mean age was 47.1 years (range 31-66 years) and the mean body mass index was $27.7 \mathrm{~kg} / \mathrm{m}^{2}$ (range $21-36 \mathrm{~kg} / \mathrm{m}^{2}$ ). Twenty patients were white and one patient was Asian. The mean total PASI score at screening was 21.47 (range 12.2-43.2) and the mean \pm standard deviation baseline serum C-reactive protein concentration was $2.0 \pm 1.7 \mathrm{mg} / \mathrm{L}$. All patients completed the study and were included in the analyses.

\subsection{Pharmacogenetics for Polymorphic Enzymes}

The metabolizer phenotypes for study participants based on pharmacogenetic analyses were as follows: CYP2C9-17 $(81 \%)$ extensive metabolizers and four (19\%) intermediate metabolizers; CYP2C19-16 (76\%) extensive metabolizers and five (24\%) intermediate metabolizers; and CYP2D6-2 (9\%) ultra-metabolizers, 17 (81\%) extensive metabolizers, 1 $(5 \%)$ intermediate metabolizer, and $1(5 \%)$ poor metabolizer. 


\subsection{Pharmacokinetics}

The mean plasma concentration-time profiles of the CYP probe drugs and their metabolites prior to risankizumab treatment and following 12 weeks of treatment with risankizumab $150 \mathrm{mg} \mathrm{SC}$ every 4 weeks are shown in Fig. 1. The concentration-time profiles of all analytes were similar before and after risankizumab treatment.

A summary of pharmacokinetic parameters of the CYP probe drugs and their metabolites is presented in Table 2. The central value ratios for $C_{\max }$ and AUC of the CYP probe drugs with risankizumab versus without risankizumab are presented in Fig. 2, and the central value ratios for the metabolite:parent AUC ratios of each drug with risankizumab versus without risankizumab are presented in Fig. 3. The central value ratios and $90 \% \mathrm{CI}$ for the $C_{\max }$ and AUC of the CYP probe drugs were all within the default equivalence limits of $0.8-1.25$ except for the $C_{\max }$ value of omeprazole, for which the lower bound of the $90 \%$ CI was 0.73 , extending slightly below 0.8 (Fig. 2). Consistent with this result, the central value ratios and $90 \% \mathrm{CI}$ for the metabolite:parent AUC ratios of 1-hydroxy-midazolam:midazolam, 5-hydroxyomeprazole:omeprazole, $\alpha$-hydroxymetoprolol:metoprolol, and paraxanthine:caffeine were also all within the $0.8-1.25$ bioequivalence limits (Fig. 3). The $t_{\max }$ and $t_{1 / 2}$ of each drug and metabolite were not affected by risankizumab (Table 2).

Consistent with data from all patients, a sensitivity analysis using data from only the patients who were extensive or ultra-metabolizers for polymorphic enzymes (CYP2C9, CYP2C19, and CYP2D6) showed no meaningful impact of risankizumab on the pharmacokinetics of the probe drugs or their metabolites; the central value ratios and $90 \%$ CI for the $C_{\max }$ and AUC for the probe drugs or their metabolites with risankizumab versus without risankizumab were within the default equivalence limits of $0.8-1.25$, except for the $C_{\max }$ value of omeprazole, for which the lower bound of the $90 \%$ CI was 0.79 , extending slightly below 0.8 . The mean trough concentration of risankizumab prior to the second, third, and fourth $150 \mathrm{mg}$ dose administration was $7.3,10.6$, and $12.0 \mu \mathrm{g} / \mathrm{mL}$, respectively. ADAs to risankizumab were detected in five of 21 (24\%) patients after risankizumab dosing. ADA titers in the patients who were ADA positive ranged from one to 16; these low-titer ADAs did not affect risankizumab exposure based on the comparable risankizumab trough concentrations in ADA-positive and ADA-negative subjects in the study (data not shown). These results are consistent with the population pharmacokinetic analysis of risankizumab conducted using data from phase I and II studies in patients with psoriasis and Crohn's disease [13].

\subsection{Safety}

Administration of the CYP probe drugs alone or with risankizumab was well-tolerated by the patients in this study. All adverse events were mild or moderate in severity and none led to discontinuation of the study drug. The only adverse event reported by more than one patient was headache, reported by two patients during treatment with risankizumab alone. One patient experienced mild pruritus and rash during treatment with risankizumab that were considered possibly related to study drug; all other events were considered not related. No clinically significant vital signs values or laboratory measurements were observed during the course of the study.

\section{Discussion}

Risankizumab is an anti-IL-23 antibody being developed for the treatment of psoriasis, psoriatic arthritis, Crohn's disease, and ulcerative colitis. This drug interaction study in patients with moderate to severe chronic plaque psoriasis evaluated the effects of risankizumab on the activity of several CYP enzymes to support dosing recommendations for commonly used concomitant medications in patients with immune-mediated inflammatory diseases. The results of this study showed that 12 weeks of dosing with risankizumab $150 \mathrm{mg}$ SC every 4 weeks had no relevant effects on the $C_{\max }$ or AUC of any of the CYP probe drugs or their metabolites, even in patients who were extensive or ultra-metabolizers based on pharmacogenetic analysis. Thus, treatment with risankizumab is not expected to cause CYP-mediated drug interactions.

The ratios and $90 \% \mathrm{CI}$ of the $C_{\max }$ and $\mathrm{AUC}_{\infty}$ of CYP probe drugs and their metabolites in the presence versus absence of risankizumab were within the default equivalence bounds of $0.8-1.25$, except for the $C_{\max }$ of omeprazole. The central value ratio for the omeprazole $C_{\max }$ during coadministration with risankizumab versus alone was 0.85 and the lower bound of the $90 \%$ CI was 0.73 ; however, the AUC value of omeprazole as well as the metabolite:parent AUC ratio were within the equivalence limits of $0.8-1.25$. Additionally, the $C_{\max }$ and $\mathrm{AUC}_{\infty}$ values of omeprazole were within the equivalence limits in patients who were extensive metabolizers of CYP2C19 $(n=16)$ based on genotyping analysis. These data suggest that the slight decrease in the omeprazole $C_{\max } 90 \% \mathrm{CI}$ to below the 0.8 boundary is likely due to the variability in omeprazole exposures across two different assessment periods and not due to drug interaction. It is noteworthy that DDI studies with a cocktail of substrates are generally not powered to meet the strict bioequivalence criteria for all evaluated exposure parameters of each component of 
Fig. 1 Mean plasma concentration-time profiles for the cytochrome P450 (CYP) probe drugs and metabolites alone and in the presence of risankizumab $150 \mathrm{mg}$ administered subcutaneously every 4 weeks for 12 weeks. Open symbols indicate CYP probe drugs and metabolites alone on day 1 ; closed symbols indicate CYP probe drugs and metabolites on day 98 after 12-weeks of treatment with risankizumab
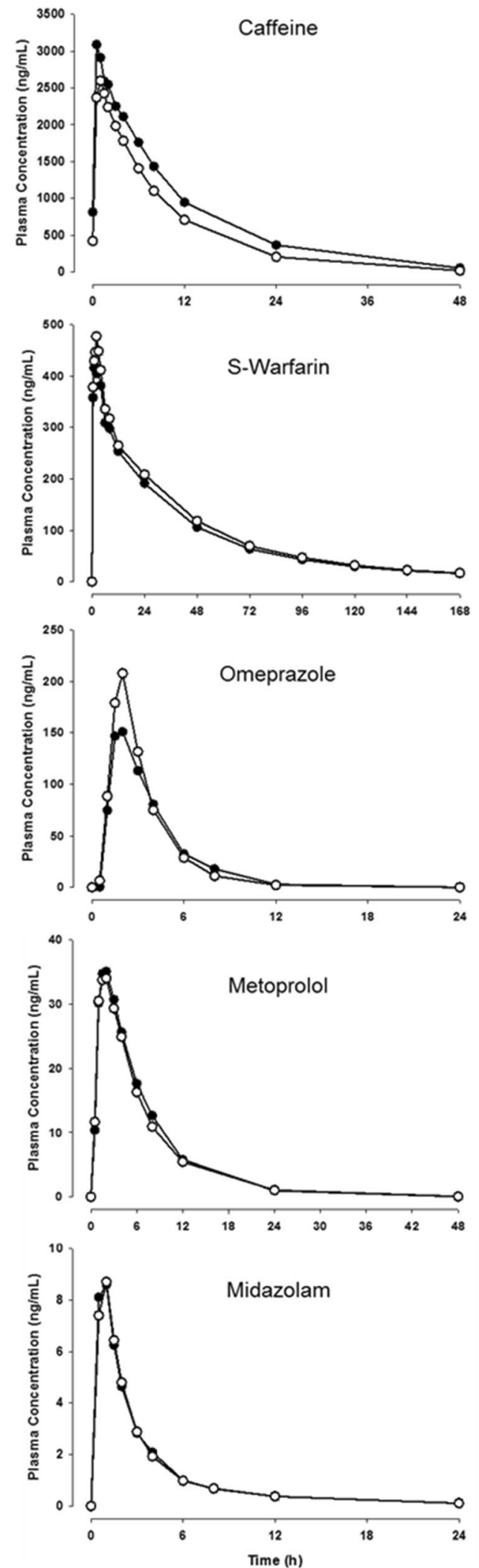
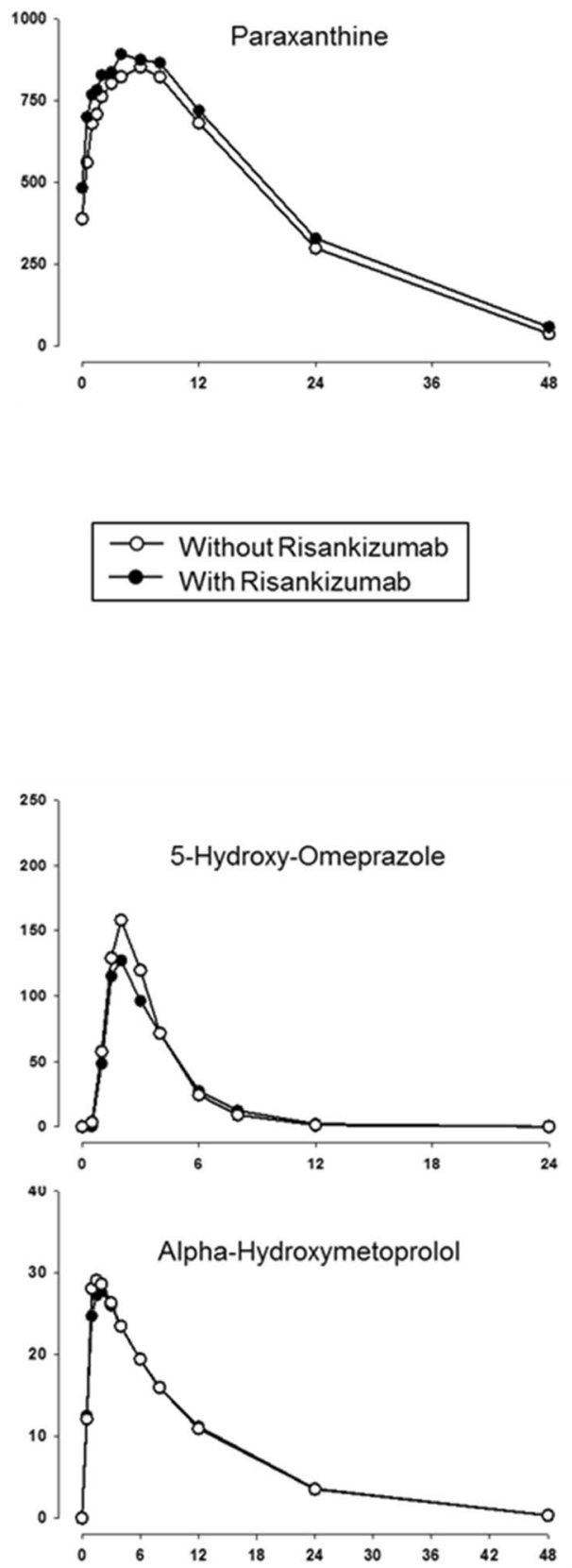

- Without Risankizumab With Risankizumab

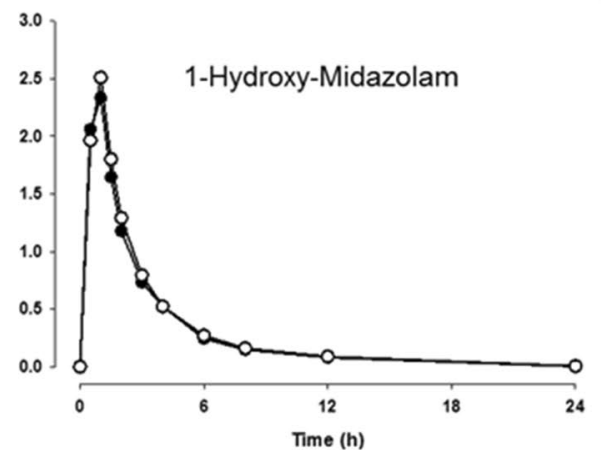


Table 2 Pharmacokinetic parameters of the cytochrome $\mathrm{P} 450$ probe substrate drugs and metabolites alone and in the presence of risankizumab

\begin{tabular}{|c|c|c|}
\hline Probe drug or metabolite & Pharmacokinetic parameter & $\begin{array}{l}\text { CYP probe alone: } \\
\text { day } 1(n=21)\end{array}$ \\
\hline
\end{tabular}

Caffeine $(100 \mathrm{mg})$
Paraxanthine

Warfarin (10 mg)

S-warfarin

$C_{\text {max }}, \mathrm{ng} / \mathrm{mL}$

$t_{\max }, \mathrm{h}^{\mathrm{a}}$

$\mathrm{AUC}_{t}, \mathrm{ng} \cdot \mathrm{h} / \mathrm{mL}$

$\mathrm{AUC}_{\infty}, \mathrm{ng} \cdot \mathrm{h} / \mathrm{mL}$

$t_{1 / 2}, \mathrm{~h}^{\mathrm{b}}$

$C_{\text {max }}, \mathrm{ng} / \mathrm{mL}$

$t_{\text {max }}, \mathrm{h}^{\mathrm{a}}$

$\mathrm{AUC}_{t}, \mathrm{ng} \cdot \mathrm{h} / \mathrm{mL}$

$\mathrm{AUC}_{\infty}, \mathrm{ng} \cdot \mathrm{h} / \mathrm{mL}$

$t_{1 / 2}, \mathrm{~h}^{\mathrm{b}}$

M:P AUC ratio $^{\mathrm{a}, \mathrm{c}}$

$C_{\text {max }}, \mathrm{ng} / \mathrm{mL}$

$t_{\text {max }}, \mathrm{h}^{\mathrm{a}}$

$\mathrm{AUC}_{t}, \mathrm{ng} \cdot \mathrm{h} / \mathrm{mL}$

$\mathrm{AUC}_{\infty}, \mathrm{ng} \cdot \mathrm{h} / \mathrm{mL}$

$t_{1 / 2}, \mathrm{~h}^{\mathrm{b}}$

Omeprazole (20 mg)

$C_{\text {max }}, \mathrm{ng} / \mathrm{mL}$

$t_{\max }, \mathrm{h}^{\mathrm{a}}$

$\mathrm{AUC}_{t}, \mathrm{ng} \cdot \mathrm{h} / \mathrm{mL}$

$\mathrm{AUC}_{\infty}, \mathrm{ng} \cdot \mathrm{h} / \mathrm{mL}$

$t_{1 / 2}, \mathrm{~h}^{\mathrm{b}}$

5-Hydroxy-omeprazole

$C_{\text {max }}, \mathrm{ng} / \mathrm{mL}$

$t_{\text {max }}, \mathrm{h}^{\mathrm{a}}$

$\mathrm{AUC}_{t}, \mathrm{ng} \cdot \mathrm{h} / \mathrm{mL}$

$\mathrm{AUC}_{\infty}, \mathrm{ng} \cdot \mathrm{h} / \mathrm{mL}$

$t_{1 / 2}, \mathrm{~h}^{\mathrm{b}}$

M:P AUC ${ }_{\infty}$ ratio $^{\mathrm{a}, \mathrm{c}}$

Metoprolol (50 mg)

$C_{\max }, \mathrm{ng} / \mathrm{mL}$

$t_{\max }, \mathrm{h}^{\mathrm{a}}$

$\mathrm{AUC}_{t}, \mathrm{ng} \cdot \mathrm{h} / \mathrm{mL}$

$\mathrm{AUC}_{\infty}, \mathrm{ng} \cdot \mathrm{h} / \mathrm{mL}$

$t_{1 / 2}, \mathrm{~h}^{\mathrm{b}}$

$\alpha$-Hydroxymetoprolol

$C_{\text {max }}, \mathrm{ng} / \mathrm{mL}$

$t_{\text {max }}, \mathrm{h}^{\mathrm{a}}$

$\mathrm{AUC}_{t}, \mathrm{ng} \cdot \mathrm{h} / \mathrm{mL}$

$\mathrm{AUC}_{\infty}, \mathrm{ng} \cdot \mathrm{h} / \mathrm{mL}$

$t_{1 / 2}, \mathrm{~h}^{\mathrm{b}}$

M:P AUC ratio $^{\mathrm{a}, \mathrm{c}}$

Midazolam (2 mg)

$C_{\text {max }}, \mathrm{ng} / \mathrm{mL}$

$t_{\max }, \mathrm{h}^{\mathrm{a}}$

$\mathrm{AUC}_{t}, \mathrm{ng} \cdot \mathrm{h} / \mathrm{mL}$

$\mathrm{AUC}_{\infty}, \mathrm{ng} \cdot \mathrm{h} / \mathrm{mL}$

$t_{1 / 2}, \mathrm{~h}^{\mathrm{b}}$

1-Hydroxy-midazolam

$C_{\text {max }}, \mathrm{ng} / \mathrm{mL}$

$t_{\text {max }}, \mathrm{h}^{\mathrm{a}}$

$\mathrm{AUC}_{t}, \mathrm{ng} \cdot \mathrm{h} / \mathrm{mL}$

$\mathrm{AUC}_{\infty}, \mathrm{ng} \cdot \mathrm{h} / \mathrm{mL}$

$t_{1 / 2}, \mathrm{~h}^{\mathrm{b}}$

M:P AUC ratio $^{\mathrm{a}, \mathrm{c}}$

$1.5(0.5-4.0)$
2870 (40)

$1.0(0.5-1.5)$

$25,100(86)$

$26,100(85)$

$5.2(1.7)$

934 (48)

$6(0.5-12.0)$

CYP probe + risankizumab: day 98 $(n=21)$

$3350(77)$

$1.0(0.5-3.0)$

33,700 (185)

35,200 (187)

$5.1(1.4)$

970 (55)

$4(0.5-12.0)$

18,200 (64)

$19,400(102)$

$20,000(63)^{\mathrm{d}}$

$17,000(38)^{\mathrm{e}}$

$8.0(2.0)^{\mathrm{d}}$

$7.9(2.3)^{\mathrm{e}}$

$0.82(0.50-1.17)^{\mathrm{d}}$

549 (24)

$0.83(0.56-1.20)^{\mathrm{e}}$

509 (29)

$1.5(0.5-12.0)$

16,800 (39)

$15,400(35)$

18,000 (41)

$16,000(35)$

46.3 (12.6)

47.5 (12.0)

265 (48)

235 (62)

$2.0(1.0-6.1)$

$2.0(1.0-8.0)$

$630(78)$

$578(76)$

$689(67)^{\mathrm{f}}$

$626(75)^{\mathrm{e}}$

$0.8(0.2)^{\mathrm{f}}$

$0.8(0.2)^{\mathrm{e}}$

$192(33)$

$178(41)$

$2.0(1.0-6.1)$

$2.0(1.5-8.0)$

$512(27)$

470 (32)

$525(27)^{\mathrm{d}}$

$1.2(0.2)^{\mathrm{d}}$

$508(27)^{\mathrm{g}}$

$1.13(0.17-1.87)^{\mathrm{f}}$

$1.2(0.2)^{\mathrm{g}}$

$1.05(0.18-4.09)^{\mathrm{e}}$

$40.6(71)$

40.8 (68)

$1.5(0.5-4.0)$

$1.5(1.0-6.0)$

253 (96)

264 (87)

257 (95)

268 (86)

$3.7(0.9)$

$3.7(0.8)$

$30.8(38)$

1.5 (1.0-8.0)

358 (35)

364 (34)

7.4 (1.6)

$1.81(0.02-11.14)$

$1.94(0.37-10.89)^{\mathrm{d}}$

$8.9(33)$

8.7 (34)

$1.0(0.5-1.0)$

$1.0(0.5-1.5)$

$28.6(40)$

$28.9(43)$

$29.9(41)$

30.3 (45)

5.0 (2.6)

$5.4(2.2)$

$2.71(45)$

$2.61(48)$

$1.0(0.5-1.5)$

$1.0(0.5-1.0)$

$7.20(38)$

$6.74(39)$

7.61 (37)

7.17 (38)

$2.9(1.1)$

$3.0(1.1)$

$0.25(0.16-0.44)$ 
Table 2 (continued)

Data are presented as mean $(\% \mathrm{CV})$ unless noted otherwise

$A U C_{\infty}$ area under the plasma concentration-time curve from time zero to infinity, $A U C_{t}$ area under the plasma concentration-time curve up to the last measureable concentration, $C_{\max }$ maximum plasma concentration, $M: P$ metabolite:parent, $t_{1 / 2}$ elimination half-life, $t_{\max }$ time to maximum plasma concentration

${ }^{a}$ Median (range)

${ }^{\mathrm{b}}$ Harmonic mean \pm pseudo-standard deviation

${ }^{c}$ Ratio of metabolite $\mathrm{AUC}_{\infty}$ to parent drug $\mathrm{AUC}_{\infty}$

${ }^{\mathrm{d}} n=20$

${ }^{\mathrm{e}} n=16$

${ }^{\mathrm{f}} n=17$

${ }^{\mathrm{g}} n=18$

$n<21$ for $t_{1 / 2}$ and $\mathrm{AUC}_{\infty}$ for analytes noted above is due to plasma concentrations below the limit of quantitation in the terminal phase

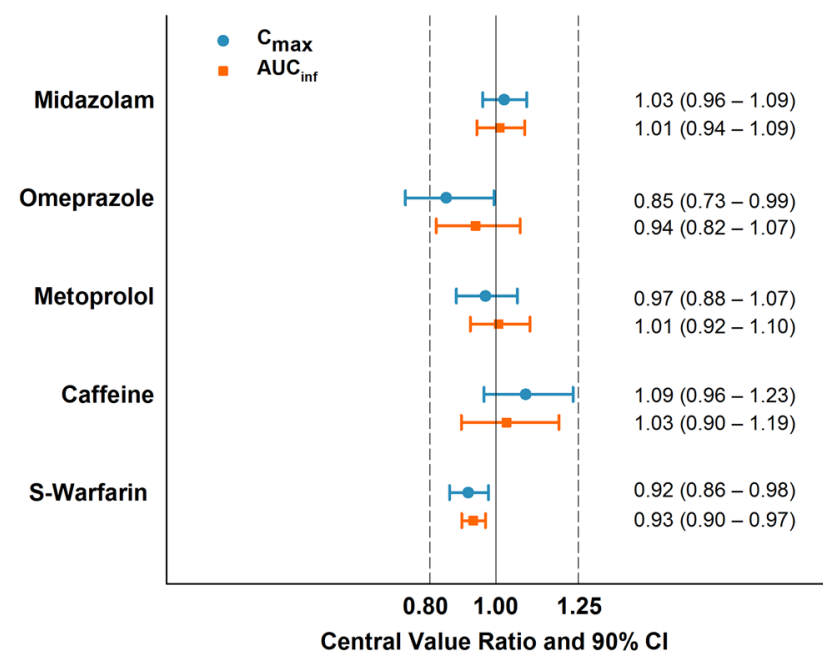

Fig. 2 Point estimates and 90\% confidence intervals (CIs) for the effect of risankizumab on the maximum plasma concentration $\left(C_{\max }\right)$ and area under the plasma concentration-time curve (AUC) values for the cytochrome P450 (CYP) probe substrate drugs. Central value ratios and $90 \%$ CIs represent the $C_{\max }$ and AUC values of the CYP probe substrate drugs administered with versus without risankizumab

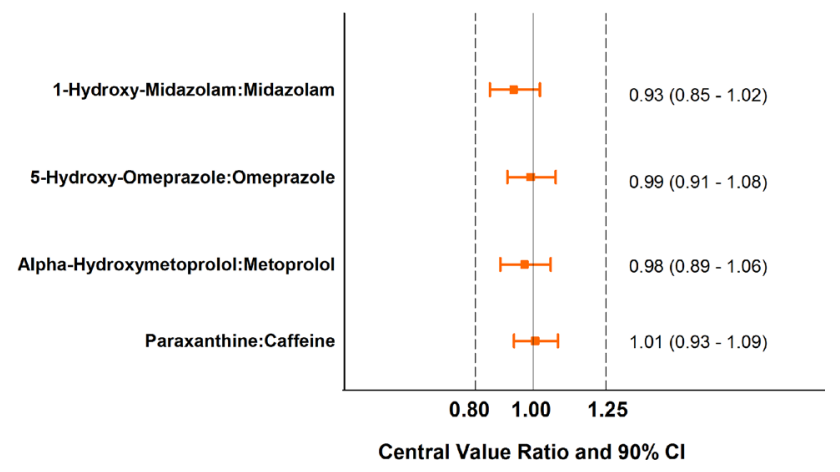

Fig. 3 Point estimates and 90\% confidence intervals (CIs) for the effect of risankizumab on the metabolite:parent drug area under the plasma concentration-time curve (AUC) ratios. Central value ratios and $90 \%$ CIs represent the metabolite:parent drug AUC ratios for the CYP probe substrate drugs administered with versus without risankizumab the cocktail. The $t_{1 / 2}$ values of all CYP probe drugs as well as their metabolites were comparable in the presence or absence of risankizumab. These data indicate that multiple dosing with risankizumab did not affect the pharmacokinetics of the drugs metabolized by CYP1A2, CYP2C9, CYP2C19, CYP2D6, or CYP3A.

In the recently completed phase III trials in patients with moderate to severe chronic plaque psoriasis, risankizumab was evaluated at a dose of $150 \mathrm{mg} \mathrm{SC}$ at weeks 0 and 4 , and every 12 weeks thereafter, and in the phase II studies in patients with psoriatic arthritis, risankizumab was evaluated at doses up to $150 \mathrm{mg}$ SC every 4 weeks [8, 9]. In the phase II study in Crohn's disease, risankizumab doses up to $600 \mathrm{mg}$ IV every 4 weeks were evaluated during induction therapy and doses of $180 \mathrm{mg}$ SC every 8 weeks were evaluated during maintenance therapy [7]. The mean risankizumab trough plasma concentration prior to the fourth dose of risankizumab in the current study $(12.0 \mu \mathrm{g} / \mathrm{mL})$ was much higher or comparable to the highest mean steady-state levels observed in various phase II and III studies in patients treated with risankizumab (more than six-fold the mean steady-state risankizumab trough concentration observed in the phase III studies in patients with moderate to severe chronic plaque psoriasis, comparable to the highest dose of $150 \mathrm{mg} \mathrm{SC}$ administered every 4 weeks in patients with psoriatic arthritis in the phase II study and more than three-fold higher than the steady-state concentration during maintenance therapy with the $180 \mathrm{mg} \mathrm{SC}$ dose administered every 8 weeks in patients with Crohn's disease; data not shown). Thus, the dose of risankizumab used in the current study, $150 \mathrm{mg} \mathrm{SC}$ every 4 weeks, is high enough to cover the plasma exposures expected in patients with moderate to severe chronic plaque psoriasis, psoriatic arthritis, or during maintenance therapy in patients with Crohn's disease.

The results observed in this study are consistent with those reported for other monoclonal antibodies targeting 
the p19 subunit of IL-23, such as guselkumab and tildrakizumab. In an exploratory drug interaction study with six to 12 evaluable subjects, a single dose of guselkumab did not result in clinically relevant changes in the AUC of midazolam, S-warfarin, omeprazole, or caffeine in patients with moderate to severe plaque psoriasis [31,32]. For dextromethorphan (CYP2D6 substrate), a 24\% increase in AUC was observed following guselkumab administration; however, at the subject-level, guselkumab had no clinically relevant effect on the AUC of dextromethorphan in nine of ten subjects in the study. Similarly, no clinically significant changes in the AUC of caffeine, warfarin, omeprazole, or midazolam were observed following administration of tildrakizumab $200 \mathrm{mg} \mathrm{SC}$ at weeks 0 and 4 in subjects with plaque psoriasis $(n=14-20)[33,34]$. The AUC of dextromethorphan was slightly (20\%) higher during coadministration with tildrakizumab. The drug interaction study of risankizumab represents a more robust assessment to demonstrate the lack of drug interaction potential of inhibiting IL-23 pathway due to a larger sample size $(n=21)$ and 12 weeks of multiple dosing, which provided risankizumab plasma exposures several-fold higher than those observed in the phase III studies in patients with plaque psoriasis. In totality, our data along with the published drug interaction studies of other anti-IL23 p19 antibodies confirm that inhibiting the IL-23 pathway is not expected to result in a clinically significant drug interaction through CYP1A2, CYP2C9, CYP2C19, CYP2D6, or CYP3A drugmetabolizing enzymes.

\section{Conclusion}

Twelve weeks of treatment with risankizumab, at a regimen that provides significantly higher plasma exposures than the phase III psoriasis clinical regimen, had no clinically relevant effect on the exposures of substrates for CYP1A2, CYP2C9, CYP2C19, CYP2D6, or CYP3A, suggesting that risankizumab is not likely to have drug interactions through these enzymes with concomitantly administered medications in patients with moderate to severe chronic plaque psoriasis.

Acknowledgements Medical writing support was provided by Allison Kitten, an employee of AbbVie. The authors and AbbVie thank the patients and investigators who participated in the trial.

\section{Compliance with ethical standards}

Funding This work was supported by Boehringer Ingelheim and AbbVie. Boehringer Ingelheim contributed to the study design and the approval of the publication. AbbVie contributed to the study design, research, and interpretation of data, and the writing, review, and approval of the publication.
Conflict of Interest AK, LC, AC, YP, and AAO are employees and shareholders of AbbVie. SI is an employee of Charite Research Organisation $\mathrm{GmbH}$, the site at which the study was performed, and has no conflicts of interest to declare.

Ethical Approval and Informed Consent The study was conducted in accordance with Good Clinical Practice guidelines and the ethical principles that have their origin in the Declaration of Helsinki. The protocol was approved by the institutional review board at the study site (Ethik-Kommission des Landes Berlin, Landesamt für Gesundheit und Soziales, Berlin, Germany) and each participant provided written informed consent prior to his or her participation in the study.

Data Sharing AbbVie is committed to responsible data sharing regarding the clinical trials we sponsor. This includes access to anonymized individual and trial-level data (analysis datasets), as well as other information (e.g., protocols and Clinical Study Reports), as long as the trials are not part of an ongoing or planned regulatory submission. This includes requests for clinical trial data for unlicensed products and indications. This clinical trial data can be requested by any qualified researchers who engage in rigorous, independent scientific research, and will be provided following review and approval of a research proposal and Statistical Analysis Plan (SAP) and execution of a Data Sharing Agreement (DSA). Data requests can be submitted at any time and the data will be accessible for 12 months, with possible extensions considered. For more information on the process, or to submit a request, visit the following link: https://www.abbvie.com/our-scien ce/clinical-trials/clinical-trials-data-and-information-sharing/data-andinformation-sharing-with-qualified-researchers.html.

Open Access This article is distributed under the terms of the Creative Commons Attribution-NonCommercial 4.0 International License (http://creativecommons.org/licenses/by-nc/4.0/), which permits any noncommercial use, distribution, and reproduction in any medium, provided you give appropriate credit to the original author(s) and the source, provide a link to the Creative Commons license, and indicate if changes were made.

\section{References}

1. Singh S, Kroe-Barrett RR, Canada KA, Zhu X, Sepulveda E, Wu $\mathrm{H}$, et al. Selective targeting of the IL23 pathway: generation and characterization of a novel high-affinity humanized anti-IL23A antibody. MAbs. 2015;7(4):778-91.

2. Gaffen SL, Jain R, Garg AV, Cua DJ. The IL-23-IL-17 immune axis: from mechanisms to therapeutic testing. Nat Rev Immunol. 2014;14(9):585-600.

3. Campa M, Mansouri B, Warren R, Menter A. A review of biologic therapies targeting IL-23 and IL-17 for use in moderate-to-severe plaque psoriasis. Dermatol Ther (Heidelb). 2016;6(1):1-12.

4. Krueger JG, Ferris LK, Menter A, Wagner F, White A, Visvanathan S, et al. Anti-IL-23A mAb BI 655066 for treatment of moderate-to-severe psoriasis: safety, efficacy, pharmacokinetics, and biomarker results of a single-rising-dose, randomized, double-blind, placebo-controlled trial. J Allergy Clin Immunol. 2015;136(1):116-124.e7.

5. Papp KA, Blauvelt A, Bukhalo M, Gooderham M, Krueger JG, Lacour JP, et al. Risankizumab versus ustekinumab for moderateto-severe plaque psoriasis. N Engl J Med. 2017;376(16):1551-60.

6. Mease PJ, Kellner H, Morita A, Kivitz AJ, Papp KA, Aslanyan $\mathrm{S}$, et al. Efficacy and safety results from a phase 2 trial of risankizumab, a selective IL-23 p19 Inhibitor, in patients with active 
psoriatic arthritis [abstract]. Arthritis Rheum. 2017;69 (suppl 10). http://acrabstracts.org/abstract/efficacy-and-safety-results-from-aphase-2-trial-of-risankizumab-a-selective-il-23p19-inhibitor-inpatients-with-active-psoriatic-arthritis/. Accessed 6 Dec 2018.

7. Feagan BG, Sandborn WJ, D'Haens G, Panes J, Kaser A, Ferrante $\mathrm{M}$, et al. Induction therapy with the selective interleukin-23 inhibitor risankizumab in patients with moderate-to-severe Crohn's disease: a randomised, double-blind, placebo-controlled phase 2 study. Lancet. 2017;389(10080):1699-709.

8. AbbVie. Risankizumab meets all co-primary and ranked secondary endpoints, achieving significantly greater efficacy versus standard biologic therapies in three pivotal phase 3 psoriasis studies [press release]. 2017. https://news.abbvie.com/news/ risankizumab-meets-all-co-primary-and-ranked-secondary-endpo ints-achieving-significantly-greater-efficacy-versus-standard-biolo gic-therapies-in-three-pivotal-phase-3-psoriasis-studies.htm. Accessed 9 Feb 2018.

9. AbbVie. Risankizumab meets all primary endpoints reporting positive results in fourth pivotal phase 3 psoriasis study [press release]. 2017. https://news.abbvie.com/news/risankizumab-meets -all-primary-endpoints-reporting-positive-results-in-fourth-pivot al-phase-3-psoriasis-study.htm. Accessed 9 Feb 2018.

10. AbbVie, A study to assess the efficacy and safety of risankizumab in subjects with moderately to severely active Crohn's disease who failed prior biologic treatment [ClinicalTrials.gov identifier NCT03104413]. 2018. US National Institutes of Health, ClinicalTrials.gov. https://www.clinicaltrials.gov. Accessed 11 Dec 2018.

11. AbbVie, A study of the efficacy and safety of risankizumab in subjects with moderately to severely active Crohn's disease [ClinicalTrials.gov identifier NCT03105128]. 2017. US National Institutes of Health, ClinicalTrials.gov. https://www.clinicaltrials.gov. Accessed 11 Dec 2018.

12. AbbVie, A multicenter, randomized, double-blind, placebo controlled induction study to evaluate the efficacy and safety of risankizumab in subjects with moderately to severely active ulcerative colitis who have failed prior biologic therapy [ClinicalTrials.gov identifier NCT03398148]. 2018. US National Institutes of Health, ClinicalTrials.gov. https://www.clinicaltrials.gov. Accessed 11 Dec 2018.

13. Suleiman AA, Khatri A, Minocha M, Othman AA. Population pharmacokinetics of the interleukin-23 inhibitor risankizumab in subjects with psoriasis and Crohn's disease: analyses of phase I and II trials. Clin Pharmacokinet. 2018. https://doi.org/10.1007/ s40262-018-0704-z (Epub 20 Aug 2018).

14. Cross RK, Wilson KT, Binion DG. Polypharmacy and Crohn's disease. Aliment Pharmacol Ther. 2005;21(10):1211-6.

15. Viktil KK, Enstad M, Kutschera J, Smedstad LM, Schjott J. Polypharmacy among patients admitted to hospital with rheumatic diseases. Pharm World Sci. 2001;23(4):153-8.

16. Gerdes S, Zahl VA, Knopf H, Weichenthal M, Mrowietz U. Comedication related to comorbidities: a study in 1203 hospitalized patients with severe psoriasis. Br J Dermatol. 2008;159(5):1116-23.

17. Lee JI, Zhang L, Men AY, Kenna LA, Huang SM. CYP-mediated therapeutic protein-drug interactions: clinical findings, proposed mechanisms and regulatory implications. Clin Pharmacokinet. 2010;49(5):295-310.

18. Mayo PR, Skeith K, Russell AS, Jamali F. Decreased dromotropic response to verapamil despite pronounced increased drug concentration in rheumatoid arthritis. Br J Clin Pharmacol. 2000;50(6):605-13.

19. Dumais $G$, Iovu $M$, du Souich $P$. Inflammatory reactions and drug response: importance of cytochrome $\mathrm{P} 450$ and membrane transporters. Expert Rev Clin Pharmacol. 2008;1(5):627-47.

20. US Department of Health and Human Services. Guidance for Industry: drug interaction studies—study design, data analysis, implications for dosing, and labeling recommendations. 2012. http://www.fda.gov/downloads/Drugs/GuidanceComplianceRe gulatoryInformation/Guidances/UCM292362.pdf. Accessed 11 Dec 2018.

21. Christensen H, Hermann M. Immunological response as a source to variability in drug metabolism and transport. Front Pharmacol. 2012;3:8.

22. Huang SM, Temple R, Throckmorton DC, Lesko LJ. Drug interaction studies: study design, data analysis, and implications for dosing and labeling. Clin Pharmacol Ther. 2007;81(2):298-304.

23. Tocilizumab [summary of product characteristics]. Welwyn Garden City: Roche. 2016. Available from: https://www.acces sdata.fda.gov/drugsatfda_docs/label/2013/125276s0921bl.pdf. Accessed 11 Dec 2018.

24. Schmitt C, Kuhn B, Zhang X, Kivitz AJ, Grange S. Disease-drugdrug interaction involving tocilizumab and simvastatin in patients with rheumatoid arthritis. Clin Pharmacol Ther. 2011;89(5):73540 (Erratum in Clin Pharmacol Ther. 2011 Sep;90(3):479).

25. Zhang X, Schmitt C, Grange S, Marino M. Disease-drug interaction studies of tocilizumab with cytochrome P450 substrates in vitro and in vivo. Clin Pharmacol Ther. 2009;85:S59.

26. Zhuang Y, de Vries DE, Xu Z, Marciniak SJ Jr, Chen D, Leon $\mathrm{F}$, et al. Evaluation of disease-mediated therapeutic protein-drug interactions between an anti-interleukin- 6 monoclonal antibody (sirukumab) and cytochrome P450 activities in a phase 1 study in patients with rheumatoid arthritis using a cocktail approach. $\mathrm{J}$ Clin Pharmacol. 2015;55(12):1386-94.

27. de Andres F, LLerena A. Simultaneous determination of cytochrome P450 oxidation capacity in humans: a review on the phenotyping cocktail approach. Curr Pharm Biotechnol. 2016;17(13):1159-80.

28. Turpault S, Brian W, Van Horn R, Santoni A, Poitiers F, Donazzolo Y, et al. Pharmacokinetic assessment of a five-probe cocktail for CYPs 1A2, 2C9, 2C19, 2D6 and 3A. Br J Clin Pharmacol. 2009;68(6):928-35.

29. Gaedigk A, Ndjountche L, Divakaran K, Dianne Bradford L, Zineh I, Oberlander TF, et al. Cytochrome P4502D6 (CYP2D6) gene locus heterogeneity: characterization of gene duplication events. Clin Pharmacol Ther. 2007;81(2):242-51.

30. Gaedigk A, Simon SD, Pearce RE, Bradford LD, Kennedy MJ, Leeder JS. The CYP2D6 activity score: translating genotype information into a qualitative measure of phenotype. Clin Pharmacol Ther. 2008;83(2):234-42.

31. Tremfya (guselkumab) [US prescribing information]. Horsham: Janssen Biotech, Inc. 2017. Available from: https://www.acces sdata.fda.gov/drugsatfda_docs/label/2017/761061s000lbl.pdf. Accessed 11 Dec 2018.

32. Center for Drug Evaluation and Research Multi-Discipline Review. Guselkumab: application number 761061Orig1s000. 2017. https://www.accessdata.fda.gov/drugsatfda_docs/ nda/2017/761061Orig1s000MultidisciplineR.pdf. Accessed 11 Dec 2018.

33. Ilumya (tildrakizumab) [US prescribing information]. Whitehouse Station: Merck \& Co., Inc. 2018. Available from: https://www. accessdata.fda.gov/drugsatfda_docs/label/2018/761067s000lbl. pdf. Accessed 11 Dec 2018.

34. Center for Drug Evaluation and Research Multi-Discipline Review. Tildrakizumab: application number 761067Orig1s000. 2018. https://www.accessdata.fda.gov/drugsatfda_docs/ nda/2018/761067Orig1s000MultdisciplineR.pdf.

35. AbbVie. This study tests the effect of risankizumab on the metabolism in the liver of five additional drugs to study possible drug interactions in patients with psoriasis with or without psoriatic arthritis [ClinicalTrials.gov identifier NCT02772601]. US National Institutes of Health, ClinicalTrials.gov. 2016-2017. https ://www.clinicaltrials.gov. Accessed 6 Dec 2018. 